\title{
Steel thixoforming, influence of forming parameters on the microstructure
}

\author{
J.C. Pierret ${ }^{1}$, A. Rassili ${ }^{1}$, G. Vaneetveld ${ }^{1}$, J. Lecomte-Beckers ${ }^{1}$, P. Cezard ${ }^{2}$, R. Bigot ${ }^{3}$ \\ ${ }^{1}$ ThixoUnit ULg, PIMW B56, University of Liège, Sart Tilman B-4000 Liège - Belgium \\ URL: www.pimw.be e-mail:jc.pierret@ulg.ac.be; a.rassili@ulg.ac.be; g.Vaneetveld@ulg.ac.be
}

${ }^{2}$ ASCOMETEL - CREAS, BP 70045, 57301 Hagondange Cedex - France

URL: www.ascometal.fr

e-mail:p.cezard@ascometal.lucchini.com;

\author{
${ }^{3}$ LGIPM, ENSAM, 4 rue Augustin Fresnel, 57078 Metz Cedex 03 - France \\ URL: $\underline{w w w . m e t z . e n s a m . f r} \quad$ e-mail: regis.bigot@metz.ensam.fr
}

\begin{abstract}
Forming of parts in the semi-solid state is quite a complex process, especially for high melting point alloys such as steel. A reason for this complexity is the amount of parameters involved in the process. Among these we could quote liquid fraction, shear rate, shape factor, contiguity, tool temperature, agglomeration level, heating rate, protecting gas, temperature distribution, lubricant... Of course all of these parameters don't have the same order of importance. In this paper we show the influence of a set of chosen parameters and we highlight their effects on the microstructure and so, on the deformation behavior. The studied parameters are the heating conditions, the tool temperature, the part temperature, the thermal exchanges between the part and the dies and the forming rate.
\end{abstract}

Key words: Thixoforming, steel, parameters, microstructure

\section{INTRODUCTION}

In this work, we study the influence of different parameters on the final microstructure of the part. For this we used a trial geometry which is formed of a kind of hollow cylinder with different widths. This variation of widths is interesting because it creates high shear rates in the part.

The most common defects occurring during the forming are cracks and porosity. They are shown on Fig. 1. These defects, which have an influence on the part quality, have been detected after analysis of the first produced parts. This leads us to investigate in order to detect their origins and make the needed improvements.

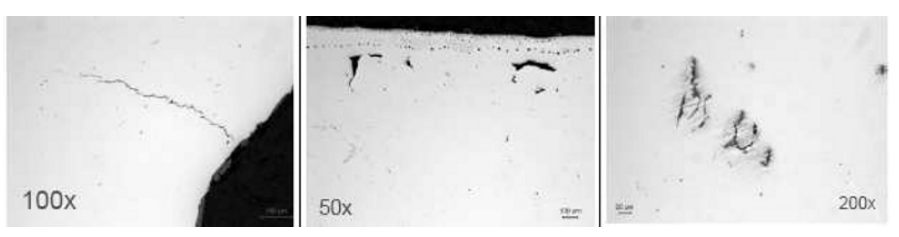

Fig. 1. Most common defects in the part

The reasons for these defects are numerous. Some cracks are due to traction during the ejection of the part because it sticks in the die. To avoid it, we increased the draft angle. But more of the cracks are due to cooling too fast. Their occurrence could be reduced by the use of heated tools and controlled cooling in an oven. Porosity is due to a high liquid fraction, fast cooling, gas entrapment or gas dissolution.

\section{RAW MATERIAL PROPERTIES}

The quality of the raw material (100Cr6LTT [1]) has an obvious effect on the final part quality. So, the steel used was analysed before any treatment in order to ensure a correct study of the processing parameters influence on the microstructure and discard the initial defects existing in the raw material.

Unfortunately, heating could create some defects in the slug. As is shown on Fig. 2, pores or cracks could appear before forming. On the top and the left of the slug we can see oxide scaling in white. We also observe pores on the bottom and cracks. These defects will be transferred to the part and so, must be reduced as much as possible. In the same way, scaling will damage the surface quality or will be included inside the part and so decreases its quality. 
The occurrence of pores could be reduced by using a lower liquid fraction if it's acceptable for the forming, so the transferring time to the press must be as short as possible to avoid a too low liquid fraction which prevents the deformation of the material.

Scaling could be reduced by the use of an inert gas such as argon during the heating. Alternatively, a coating of the billet could be helpful. Finally, a shorter heating time decreases the scaling as oxidation has less time to appear. If we use argon, decreasing the heating time also decreases the needed quantity of argon and so the price of the formed part.
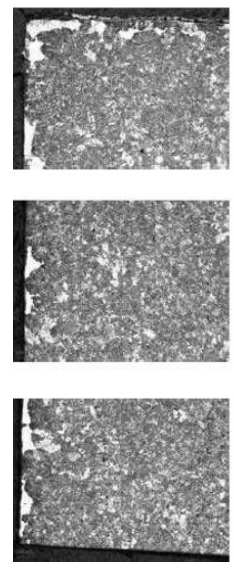

Fig. 2. Structure of the slug at the end of the heating

\section{INITIAL TEMPERATURE HOMOGENEITY INFLUENCE}

It is obvious that the slug's temperature homogeneity will have an influence on the part's microstructure homogeneity. Unfortunately, this homogeneity is very difficult to obtain.

\subsection{Influence of the boundary conditions}

Figure 3 shows the evolution of the temperature inside the slug during heating. The billet is placed in the middle of the inductor and stands on a ceramic pedestal. Only a half of the billet is shown because the FEM simulations are performed in a 2-D Axisymetric model.

In inductive heating, the energy penetrates in the billet only a short depth, which is called the penetration depth. In a second of time, the heat diffuses by conduction inside the billet but the boundary conditions being not the same, the temperature evolution is also different. As the slug is put on a ceramic plate, it is isolated and the heat is well retained but the top and the lateral part are on contact with the argon flow and the thermal exchanges are more important. The heat enters by the lateral surface and escapes by the top and the lateral face. So the hottest zone is the bottom centre and the coldest one is the external top. The hottest part could lead to defects as showed in section 2 but the coldest part could prevent deformation. To have good part properties, it is better to reduce as much as possible the temperature difference between the hottest and the coldest points.

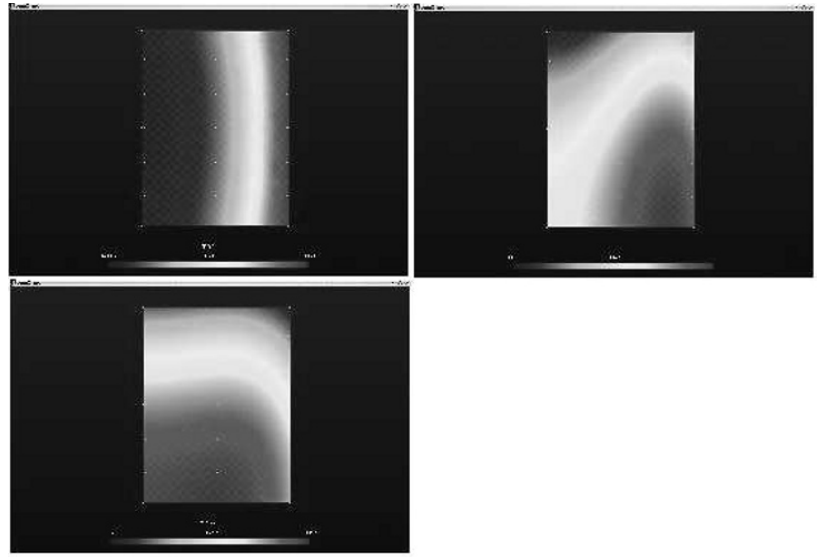

Fig. 3. Evolution of the temperature in the slug

It could also be useful to place the billet in the tool in a way that the hottest part will be the most deformed one.

\subsection{Effect of the inductor shape}
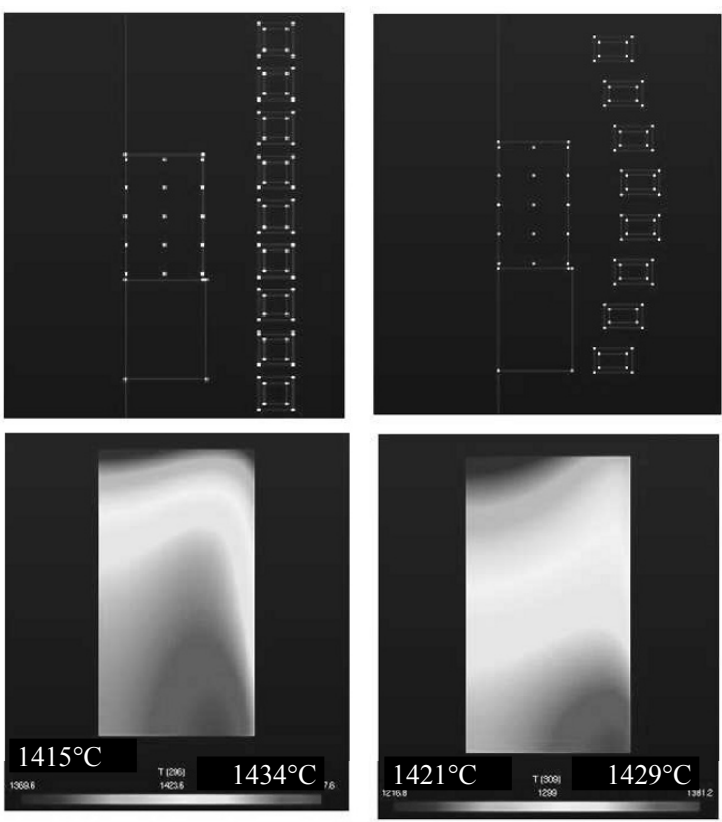

Fig. 4. Inductors geometries and final temperature distribution

Previous work [2] showed that the shape of the inductor has an influence on the temperature distribution. Figure 4 shows the final temperature 
distribution at the end of heating for two different inductor geometries. First inductor has a classical cylindrical shape and second one has a parabolic shape. As expected, the homogeneity is better with the parabolic shape where the difference between the hotter and the colder spot is half that for the other inductor.

\section{DECREASING THE THERMAL EXCHANGES}

Thermal effects are responsible of the freezing flow which has an impact on the final shape of the part but also on its quality by freezing the defects. When the material is solid, pores couldn't be reduced and cracks appear more easily. As well, the forming load increases drastically.

There are numerous ways to decrease the thermal exchanges, among which, we could cite heating or insulation of the tool, lubricant and forming speed

\subsection{Heating and isolation of the tool}

The tool could be heated by using heating collars. In order to improve the isolation of the tool, and so decrease the thermal losses, we used a ceramic plate between the die and the rest of tooling. It allows to increase the working temperature of the tool. During this work, we heated the dies up to $350^{\circ} \mathrm{C}$. This temperature allows a reduction of the forming load of approximately $20 \%$ as also reported by P. Cezard and al.[3].

\subsection{Lubricant effect}

We used two lubricants during this study : boron nitride water suspension and ceraspray. The ceraspray is a kind of ceramic spray which acts as a lubricant to decrease the friction and so the wearing but it also decreases the thermal exchanges between the slug and the dies [4]. By using it, we observe a decrease of the forming load and it was easier to reach the final geometry of the part. Preventing the freezing flow, it also reduces the defects inside the part. As the two lubricants have a quite similar effect on the friction we prefer to use the ceraspray.

\subsection{Forming speed}

By increasing the forming speed, we decrease the forming time and so the thermal exchanges between the slug and the dies. In the same time, it increases the shear rate and has been shown $[5,6,7]$ that a high shear rate decreases the material viscosity. These two effects are difficult to decorrelate but increasing the forming speed of $50 \%$ leads to a decrease of the forming load of approximately $15 \%$ in our experiments.

\section{OXIDATION}

Scaling occurs mainly during inductive heating. As mentioned in section 2 , this scaling could be reduced by using argon as a protective atmosphere or a coating of the billet or by reducing the heating time, even if it leads to less homogeneity. Nevertheless, scaling also occurs during the transfer between the inductive furnace and the press and during the forming step itself. It is possible to use argon during the transfer and so reduce the scaling. Figure 5 shows the oxide layer comparing with and without argon.

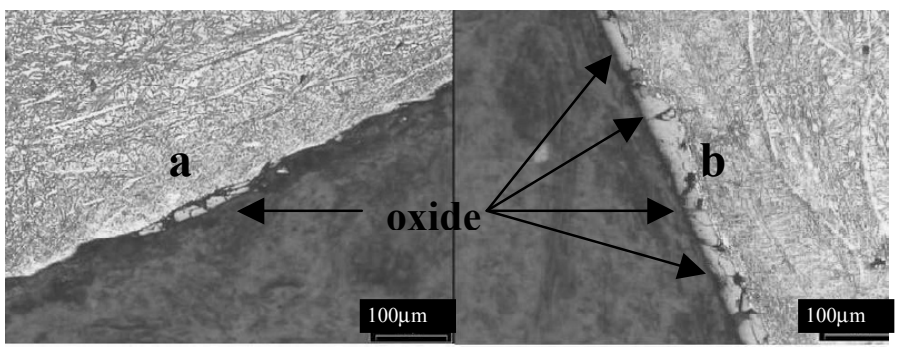

Fig. 5. Oxide layer with (a) or without (b) argon

\section{HEAT TREATMENT}

\subsection{Controlled cooling}

In order to improve the microstructure we put the part in an oven at $650^{\circ} \mathrm{C}$ for two hours just after the forming and we let it cool slowly. This controlled cooling leads to a better homogeneity of the structure. This improvement is shown by the hardness distribution in the part (Table 1). We then moved from a globally pearlitic structure with a large amount of martensite and a bit of lederburite to a globally pearlitic structure with a bit of lederburite and almost no martensite. Figure 6 shows the different microstructures obtained.

Table 1. Influence of controlled cooling on Vickers hardness distribution $(\mathrm{P}+\mathrm{M}=$ Pearlite plus Martensite $)$

\begin{tabular}{l|l|l|l|l}
\hline Part number & 1 & 2 & 3 & 4 \\
\hline Cooling & air & air & oven & oven \\
\hline Structure & $\mathrm{P}+\mathrm{M}$ & $\mathrm{P}+\mathrm{M}$ & $\mathrm{P}$ & $\mathrm{P}$ \\
\hline 1 & 421 & 477 & 359 & 374
\end{tabular}




\begin{tabular}{l|l|l|l|l}
2 & 427 & 450 & 350 & 363 \\
3 & 422 & 448 & 345 & 361 \\
4 & 413 & 416 & 351 & 365 \\
5 & 420 & 413 & 348 & 366 \\
6 & 407 & 391 & 338 & 359 \\
7 & 436 & 439 & 357 & 365 \\
8 & 443 & 444 & 369 & 380 \\
\hline Average & 424 & 435 & 352 & 367 \\
\hline Std. deviation & 12 & 27 & 9 & 7 \\
\hline
\end{tabular}
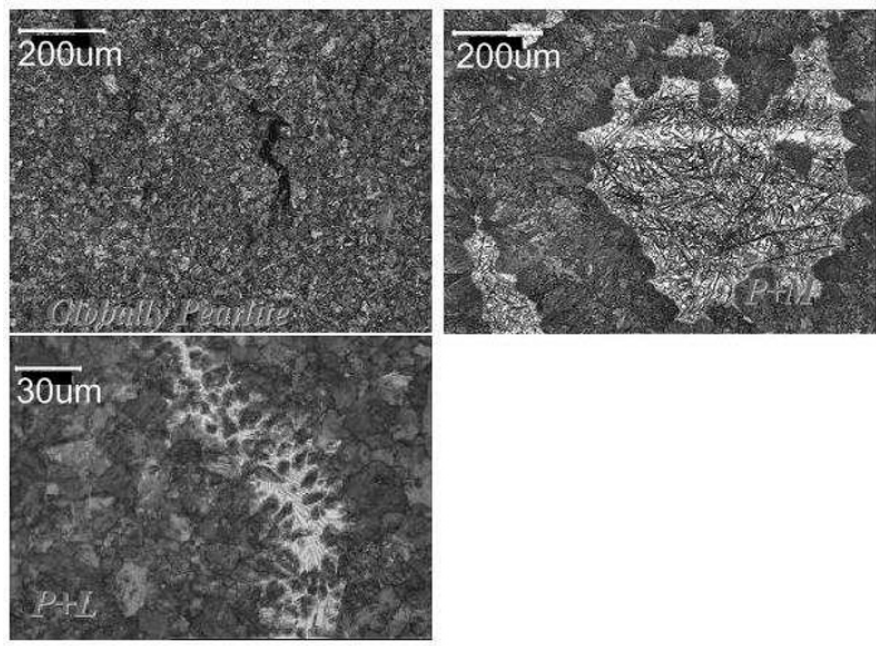

Fig. 6. Different structures obtained

\subsection{Heat treatment}

Alternatively to the controlled cooling, it is also possible to use a heat treatment after the forming and the cooling of the part. Table 2 shows the effect of different thermal treatment on the hardness distribution, and so on the homogeneity of the part.

Table 2. Influence of thermal treatment on the Vickers hardness distribution

\begin{tabular}{l|l|l|l|l}
\hline Area & Thixoformed & $\begin{array}{l}\text { Annealed } \\
\left(650^{\circ} \mathrm{C}\right)\end{array}$ & Glubolized & $\begin{array}{l}\text { Normalised } \\
\left(950^{\circ} \mathrm{C}\right)\end{array}$ \\
\hline 1 & 664 & 419 & 218 & 278 \\
2 & 656 & 431 & 224 & 294 \\
3 & 647 & 427 & 221 & 290 \\
4 & 670 & 419 & 220 & 291 \\
5 & 686 & 424 & 220 & 289 \\
6 & 693 & 412 & 218 & 281 \\
7 & 580 & 423 & 225 & 289 \\
8 & 599 & 430 & 223 & 289 \\
\hline Average & 649,4 & 423,1 & 221,1 & 287,6 \\
\hline Std. & 40,1 & 6,4 & 2,6 & 5,3 \\
Deviation & & \multicolumn{3}{|l}{}
\end{tabular}

It appears that all the thermal treatments lead to a lower hardness but mainly to a better homogeneity of this hardness and so on the structure homogeneity. If we observe directly the microstructure we nevertheless see that the normalised part's quality is the best one and the $650^{\circ} \mathrm{C}$ annealed one is the second worst after the asthixoformed one.

\section{CONCLUSIONS}

Most of the forming parameters have an impact on the microstructure and it's established than this structure and its evolution lead the slurry behaviour. The material flow, as well as the forming load, are directed by this structure.

Unfortunately, these parameters are often coupled and the influence of each one is hard to determine. For instance, a modification of the forming speed, the heating strategy or the tool temperature has an impact on the thermal exchanges between the part and the dies. At the opposite, a quite bad structure could be highly improved by heat treatment if there are not too much defects in the part.

\section{ACKNOWLEDGEMENTS}

The authors gratefully acknowledge the University of Liège, the First Europe Project, Walloon Region and the COST541 action for their financial support.

\section{REFERENCES}

1. M. Robelet, A. Rassili and D. Fischer : Steel grades adapted to the thixoforging process, metallurgical structures and mechanical properties, Trans. Tech Publications, Solid State Phenomena Vols. 116-117, Switzerland, 2006.

2. A. Rassili, C. Geuzaine, W. Legros, M. Bobadilla, A. Cucatto, M. Robelet, S. Abdelfattah, J. Dohmann, Ch. Hornardt, Simulation of adequate inductive heating parameters and the magneto-thermal coupling involved in the SSM processing of steels, $6^{\text {th }}$ International Conference Semi-Solid Processing of Alloys and Composites, Turin 2000.

3. P. Cezard, R. Bigot, V. Favier, M. Robelet, Thixoforming of steel - Influence of thermal parameters, Solid State Phenomena, vol 116-117 (2006), 721-724

4. P. Cezard, Impact des effets thermiques sur le comportement du materiau lors de la mise en forme des aciers à l'état semi-solide: analyse expérimentale et numérique, PhD thesis, ENSAM, 2006

5. P. Kumar, C. Martin, S.B. Brown, Shear rate thickening behavior of semi-solid slurries, Material and Metallurgical Transaction A 24 (1993), 1107-1116

6. D.H. Kirkwood, Semi-solid metal processing, International Material Reviews 39 (1994), 173-189

7. Z. Fan, Semi-solid metal processing, International Material Reviews 47 (2002), 49-85 